\title{
SAVREMENO GRAĐENJE OBJEKATA I SAVREMENA KLIZIŠTA
}

Đurić N. ${ }^{1}$

UDK: 624.131 .542

DOI:10.14415/konferencijaGFS 2016.048

Rezime: Građenje objekata kao jedan od najstarijih zanata se tokom vremena razvijalo do te mjere da danas predstavlja značajnu naučnu oblast. Izgrađeni su brojni objekti iznad $i$ ispod zemlje tokom pretekle ljudske civilizacije. Neki su bili manje ili više značajni, ali u osnovi svi su imali jedinstven cilj da budu što kvalitetniji i dugotrajniji. Koliko se u tome uspijevalo? Ranije znatno manje, a danas se traži da imaju potpunu sigurnost $i$ dugotrajnost. Intenzivno građenje tokom XX $i$ početkom XXI vijeka zahtijevalo je pored razvoja građevinske nauke, razvoj $i$ drugih nauka, prvenstveno geoloških koji proučavaju stijenske mase na kojima se i u kojima se grade objekti. Razvijena je posebna naučna oblast geotehnike koja obuhvata inženjerskogeološka proučavanja karakteristika terena i stijenskih masa u prirodnom stanju, koja služe kao podloga na osnovu koje se planiraju $i$ grade određeni objekti. Danas nema u vazduhu građevinskih objekata, svi su vezani za površinu ili nepostredno ispod površine terena, što zaghtijeva njegovo detaljije proučavanje. Građevinska nauka je dostigla visok stepen savršenstva u dijelu stabilnosti konstrukcija objekata, ali je još uvijek korak iza u dijelu povezivanja konstrukcije objekta sa podlogom na kojoj se ili u kojoj se gradi.

Intenzivna gradnja objekata krajem XX $i$ početkom XXI vijeka koja se poklopila sa promjenom društveno svojinskih odnosa, djelimično je zapostavila dosadašnja planska građenja, kako po pitanju korištenja prostora tako i načina građenja. Izostaje djelimično a negdje i potpuni dio prethodnih priprema u dijelu proučavanja karakteristka terena $i$ projektovanje objekata usaglašenih sa terenom. Sve se brzo gradi ne vodeći računa o kvalitetu gradnje $i$ eventualno posljedicama tokom i nakon građenja. Posebno je izraženo kod objekata niskogradnje, prvenstveno linijskih objekata. Ovaj period može se nazvati period "savremene gradnje objekata", koji nije organizaciono, stručno i naučno tako izdvojen, ali se sam nametnuo. Negativni rezultati građenja objekata u tom periodu su vidljivi tokom ili nakon izgradnje, a posebno u vrijeme intenzinih padavina, koje su ovo područje tri puta zahvatile u posljednje tri godine. Elementarne nepogode su opomena za sve ono što je loše urađeno ili propušteno da se utradi kod građenja objekata, te da se ponovo vratimo periodu dobre izučenosti terena i boljem kvalitetu građenja. Ova razmišljanja nastala su nakon obilaska većeg proja klizišta u Bosni $i$ Hercegovini, koja su rađenu u okviru jednog od projekata UNDP-a, a u radu je pored osvrta na nastalu problmatiku dat i prikaz nekih krakterističnih klizišta.

Ključne riječi: savremena gradnja, klizišta, inženjerske aktivnosti, padavine, posljedice

\footnotetext{
${ }^{1}$ Prof. dr Neđo Đurić, Univerzitet u Novom Sadu, Građevinski fakultet Subotica, Kozaračka 2a, Srbija. e.mail.nedjodjuric10@g.mail.com
} 
Contemporary achievements in civil engineering 22. April 2016. Subotica, SERBIA

\section{UVOD}

Građenje objekata vezano stijenske mase kao prirodnu sredinu, gdje dolazi do narušavanja njenog ravnotežnog stanja, koje može da se manifestuje na različite načine, od kojih neki ostavljaju posljedice na objekat koji se gradi, sredinu gdje se nalazi ili zajedno na objekat i prirodnu sredinu. Nema građenja objekata, odnosno inženjerskih aktivnosti na terenu, a da se ne narušava prirodna sredina. Ipak, nisu samo aktivnosti čovjeka koje mi u savremeno doba nazivamo inženjerske aktivnosti jedini uzrok narušavanja prirodne ravnoteže. Ima ih više, ali čovjek koji zajedno živi sa prirodom od nje često više uzima nego što daje, tako da je priroda ponekad "surova" i ostavi čovjeku ili ljudskoj civilizaciji takve posljedice, kao opomenu da se o njoj treba više razmišljati. Narušavanje prirodne sredine vezano je i za nastanak Zemlje kao planete i razvoj Zemljine kore tokom geološke istorije. Svi procesi koji su nastali tokom geološke istorije praćeni su određenim prirodnim zakonitostima koje su oblikovale površinski dio Zemljine kore, sve do pojave ljudske civilizacije i njene potrebe da se od prirode uzme ono što je potrebno za njihov opstanak i razvoj.

Istorija građenja objekata i eksploatacije mineralnih resursa vezana je za narušavanje prirodne ravnoteže, odnosno geološke sredine u kojoj se odvijaju ljudske aktivnosti. U kojoj mjeri su više ili manje uticaja imale građevinske ili rudarske aktivnosti, teško je odrediti. Ipak posljednjih nekoliko stotina godina, a posebno prethodni vijek karakeriše intenzivnu građevinsku aktivnost na polju izgradnje različite vrste objekata kako na površini zemlje, tako i kod izgradnje podzemnih objekata.

Građevinska aktivnost, posebno na površini terena često narušava njegovo pirodno stanje ravnoteže, što se manifestuje stvaranjem različitih savremenih egzogenih procesa, a time i posljedica po objekte, ali i prirodnu sredinu u bližoj ili široj okolini. Česte vremenske promjene tokom godine koje se manifestuju u temperaturnim razlikama i količinama padavina, samo pospješuju proces narušavanja stabilnoti terena, ponekad do te mjere da su posljedice velike, pa čak i katastrofalne.

Potreba ljudske civilizacije da mijenja prirodu i prilagodi je sebi, takođe je vezana i za stalno usaglašavanje objekata sa prirodom, kako bi se izbjegle neželjene posljedice. Koliko se u tome uspijeva, vječna je dilema, posebno kada se pojave posljedice na objektima. Da li su posljedice rezultat stihijskih procesa ili inženjerskih aktivnosti, odnosno nedovoljnog prouačvanja prirodne sredine i usaglašavanja objekta sa njom?

Velike količine padavina koje su posljednjih godina prisutne na ovom području, narušavaju prirodno stanje ravnoteže, koje se manifestuje u stvaranju savremenih egzogenih procesa na padinama i duž riječnih tokova, pri čemu dolazi do oštećenja ili potpunog uništenja već izgrađenih objekata.

Padavine tokom maja 2014 godine, marta 2015 godine, ali i novije 2016 godine, zahvatile su neka područja država Srbije, BiH i Hrvatske i ostavile takve posljedice, da se više počelo razmišljati, koliko je to rezultat stihijskih procesa, a koliko ljudske nezainteresovanosti da se kvalitetnijim pristupom gradnje i eksploatacije objekata preduprijede takve pojave. Često se otvara pitanje da li je tako moralo biti?

Najznačajnije pojave narušavanja stabilnosti terena vezane su za klizišta, kojih je u posljednje dvije godine bilo u tolikoj mjeri da se može izvesti sasvim pouzdana konstatacija o presudnoj ulozi čovjeka kao faktora koji stvara antopogene procese takve da su pogodni za narušavanje prirodnog stanja ravnoteže. 
U kojoj mjeri su navedene pojave dovele do narušavanje prirodne ravnoteže i koliko su vezane za stihijske procese ili inženjerske aktivnosti, teško je odvojiti, ali sve analize pokazuju da se o njima raspravlja samo kada se dogode i da se brzo zaborave sa novim početkom građenja objekata.

Razvoj tehnike građenja i proučavanja karakteristika terena ne prati stabilnost izgrađenih objekata tokom vremena. Danas postoji dovoljno znanja i tehnike da se objekti mogu uspješno graditi i održavati tokom njihove eksploatacije, ali povremeno ove aktivnosti nisu usaglašene, što se odražava na kvalitet gradnje i održavanja objekata. Analizirani period intenzivne gradnje objekata od polovine XX vijeka izdvaja period do devedesetih godina koji se može nazvati racionalnim periodom. Kasnije od devedesetih godina XX vijeka, te početak XXI vijeka, obuhvata vrijeme brze gradnje objekata, koja često ostavlja takve posljedice na terenu da ponekad prevazilaze vrijednost izgrađenih objekata.

\section{SAVREMENO GRAĐENJE OBJEKATA, POSLJEDICE TOKOM I NAKON IZGRADNJE}

Termin savremeno građenje objekata se ne odnosi na tehnička dostignuća u ovoj oblasti, već za noviji period vezan za države u tranziciji, koje su se našle između dosadašnjeg načina građenja i usklađivanja sa načinom građenja objekata u novim uslovima koji vladaju u zemljama Evropske Unije [1]. Nastao je period brze gradnje, gdje izostavljen redosljed građenja objekata od pripreme i izrade dokumentacije do njihovog izvođenja. Sve se zasniva na brzom projektovanju i "doprojektovanju" u fazi izgradnje objekta. U znatnoj mjeri su zapostavljena geološka i inženjerskogeološka istraživanja terena, čije karakteristike predstavljaju podlogu za projektovanje i temeljenje objekata, te uređenje prostora oko njih i mjere zaštite tokom njihove eksploatacije. Često se značajni objekti projektuju, a da se ne znaju ni osnovne karakteristike terena, odnosno istraživanja su djelimična ili ih skoro da i nema. Ako se tome doda još i kvalitet nadzora tokom izgradnje objekata, onda se posljedice koje su nastale u prethodnom periodu od strane povećanih padavina, mogu lakše objasniti.

Navedene konstatacije su preduslov za razvoj savremenih inženjersko-geoloških procesa, koji se manifestuju u vidu klizišta ili drugih egzogenih procesa. Posljedice takvih procesa su narušavanje stabilnosti terena, koje može ostati ne zapaženo u ne urbanim terenima, pa do potpunog ugrožavanja izgrađenih objekata. Najviše se javljaju tokom ili nakon izgradnje, prvenstveno linijskih infrastrukturnih objekata, nešto manje stambeno-poslovno-proizvodnih, a prisutni su u nekoj mjeri kod izgradnje bilo koje vrste objekata. [1,2,3].

Pojava većeg broja klizišta poslije navedenih padavina najjednostavnije je povezati sa stihijskim procesima koji su vezani za elementarne nepogode. Zajedničko je stihijski ali i antropogeni procesi, obzirom da je najveći dio klizišta vezan za inženjerske aktivnosti na terenu. Takva klizišta su bila prisutna i ranije [4,5], posebno tokom i nakon izgradnje određenih objekata, ali su ova koja su nastala poslije izuzetno visokih padavina nastala $u$ većem broju, pa čak i tamo gdje se realno nisu očekivala. Ostaje pitanje da li je tokom građenja propuštena neka faza kvalitetnije gradnje ili održavanja tokom vremena, 
Contemporary achievements in civil engineering 22. April 2016. Subotica, SERBIA

odnosno da li su stvoreni novi uslovi na terenu koji su podloga za razvoj savremenih egzogenih procesa, prvenstveno klizišta, koja se mogu nazvati "savremena klizišta".

Termin "savremena klizišta" nije poznat u literaturi niti je odomaćen u praksi, ali se može povezati sa određenim vremenskim periodom. To su pojave nastale nakon brze gradnje objekata, bez prethodnih istraživanja i urađene projektne dokumentacije [1]. Vezane su za sve geološke sredine od uslovno stabilne do nestabilne ravnoteže. Kao složen problem po pitanju posljedica nakon njihovog nastanka, ali sasvim rješiv u fazi prethodne pripreme za izgradnju objekata, klizišta kao egzogeni proces u prirodnom stanju ili inženjerskogeološka pojava nakon inženjerskih aktivosti, zahtijevaju proučavanje u okviru više naučnih oblasti. Problematika se uglavnom nalazi između geologije i građevinarstva, odnosno nove naučne oblasti geotehnike, koja se postepeno razvija i na ovim prostorima [1].

Uloga geološke nauke je veoma značajna u dijelu proučavanja karakteristike terena i prezentiranja projektantima uslova za projektovanje sigurnih objekata [6,7]. Koliko se geološka nauka približila građevinskoj, odnosno koliko je građevinska bliža geologiji, ne može se jasno definisati, ali se može sagledati na posljedicama koje nastaju nakon izgradnje objekata. Navedena problematika samo pripada naučnim oblastima, ali nije nauka jer je dobro poznata. Ostaje činjenica da kod proučavanja terena i građenja objekata nije uvijek bio adekvatan pristup.

\section{NEKOLIKO PRIMJERA KARAKTERISTIČNIH KLIZIŠTA}

Intenzivne padavine u posljednje tri godine su takve da su stvorile uslove za nastanak nekoliko hiljada klizišta na području tri navedene države. Najviše ih je bilo u sjevernoj i istočnoj Bosni, te zapadnoj i centralnoj Srbiji, obzirom ka karakteristike terena i značajnoj inženjerskoj aktivnosti. Sva su različita po veličini, obliku, vrsti sredine u kojoj su nastali i ostalim elementima klizišta, a rezultat su dva faktora, koji se ogledaju u stihijskim i antropogenim procesima. U kojoj mjeri je neki od navedena dva faktora imao značaj nije teško odrediti u uslovima nastanka klizišta gdje nema objekata. Ova klizišta nisu u dovoljnoj mjeri ni registrovana, jer nisu predmet interesovanja čovjeka, ostala su samo kao prirodna pojava.

Klizišta nastala u dijelu terena koja ugrožavaju izgrađene objekte do te mjere da je većina potpuno uništena, traže odgovor jesu li ona rezultat stihijskih procesa ili inženjerskih aktivnosti koje stvaraju antropogene procese.

Znatan dio klizišta se javio kao rezultat indirektnog uticaja čovjeka usljed narušavanja prirodne ravnoteže tokom sječe šuma, eksploatacije građevinskih materijala iz površinskog dijela terena ili riječnih vodotoka, te nedovoljna obrađenost poljoprivrednih padinskih površina $[1,2,3,8]$. Neka od ovih klizišta imala su i uticaj na ugrožavanje objekata.

Karakteristična su klizišta duž trase putnih saobraćajnica, bilo da sa su iznad ili ispod njih. U dijelovima trase gdje su istraživanja detaljnije provedena, stabilizovane su uslovno stabilne padine i ostale su stabilne i poslije navedenih perioda. Slabije istraženi dijelovi trase saobraćajnica nisu u dovoljnoj mjeri obuhvatili proučavanje njihovih karakteristika, tako da su uslovno stabilne padine oštetile trasu i objekte na trasi, neke i potpuno uništile. 
$\mathrm{Na}$ trasi regionalnog puta Drinjača kod Zvornika - Bratunac, koja skoro cijelom dužinom prolazi pored lijeve obale rijeke Drine, pojavio se veći broj klizišta. Trasa puta rađena je početkom XX vijeka tokom Austro-ugarskog perioda. Jedna strana puta je usječena u padinu koja se prostire prema rijeci Drini, a druga strana puta u većem dijelu trase sa različitim nagibom pada prema rijeci. Put je makadamskog tipa i korišten je oko 100 godine bez većih oštećenja. Početkom XXI vijeka započeto je asfaltiranje puta, što je zahtijevalo, njegovo proširivanje i osavremenjivanje.

Radovi su započeti bez prethodno urađene geološke dokumentacije i veoma loše ostale dokumentacije. Izvođeni su u najnepovoljnijem zimskom periodu. Rezultat takvog rada je veliki broj klizišta u dijelu zasječnog terena i otkidanja ispod puta prema rijeci Drini. Neka klizišta su sanirana u hodu, a neka su bila u takvoj mjeri da su zahtijevala detaljnija istraživanja i proučavanja, na osnovu čega su rađena projektna rješenja. Jedno od klizišta koje se nije moglo kvalitetno premostiti u toku gradnje, a bez detaljnijeg proučavanja terena i izrade glavnog projekta je Polom $[9,10]$.

Nakon istraživanja terena, gdje su istražne bušotine u pojedinim dijelovima bile preko $30,0 \mathrm{~m}$ dubine, urađen je projkat sanacije koji se sastojao od kombinacije šipova potpornih zidova i podzemnih drenaža, slika 1 .
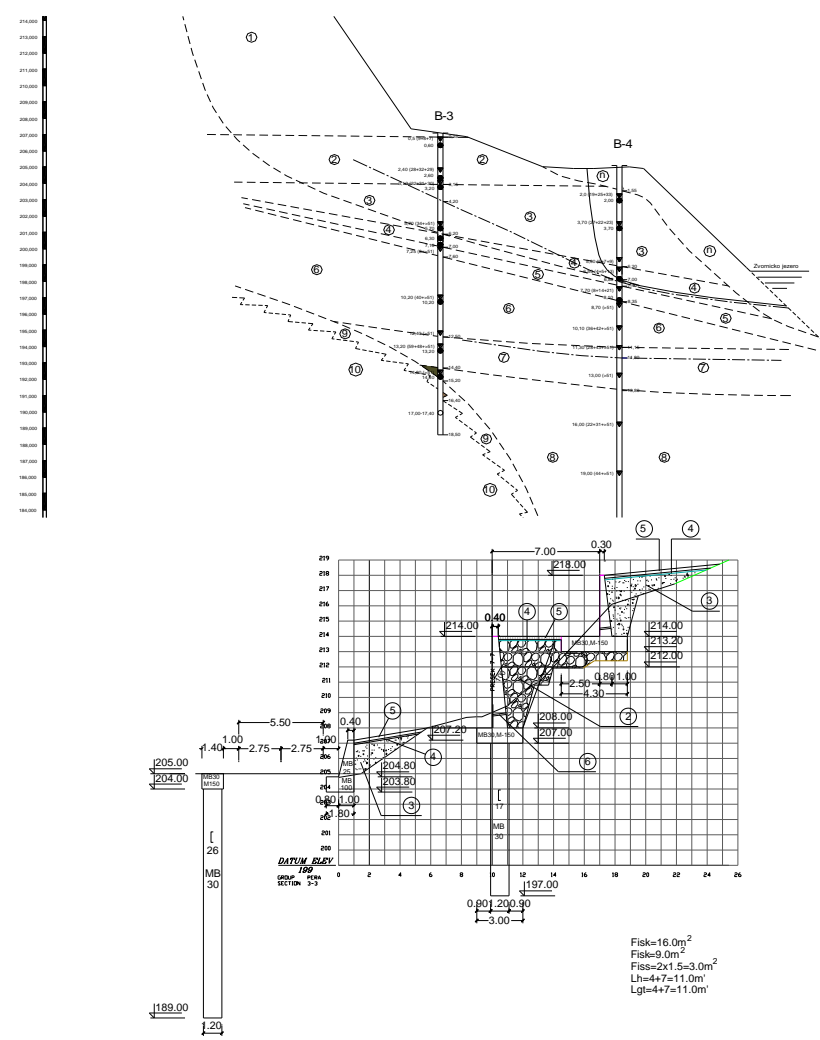

Slika 1. Klizište „Polom“ na regionalnom putu Drinjača - Bratunac, sanirano kombinacijom šipova i potpornih zidova 
Contemporary achievements in civil engineering 22. April 2016. Subotica, SERBIA

Klizišta koja nisu tada sanirana ili su sanirana $\mathrm{u}$ hodu, poslije prvih padavina $\mathrm{u}$ proljetnom periodu su aktivirana, a na pojedinim dijelovina duž trase nastala su nova klizišta koja ranije nisu postojala. Ovdje se može naglasiti da je sva problematika nastala kao rezultat nedovoljne istraženosti i proučenosti terena, tako da se građevinskim radovima narušila i uslovno stabilna ravnoteža na pojedinim padinama. Intenzivnije padavine u posljednje tri godine pokazale su da su tada kvalitetno urađene sanacije terena odolile stihijskim procesima i ostale u stabilnom stanju. Ostali dijelovi trase puta su oštećeni sa jedne i druge strane, odnosno teren klizi ka trasi puta ili se otkida ispod puta i klizi ka rijeci, slika 2 .
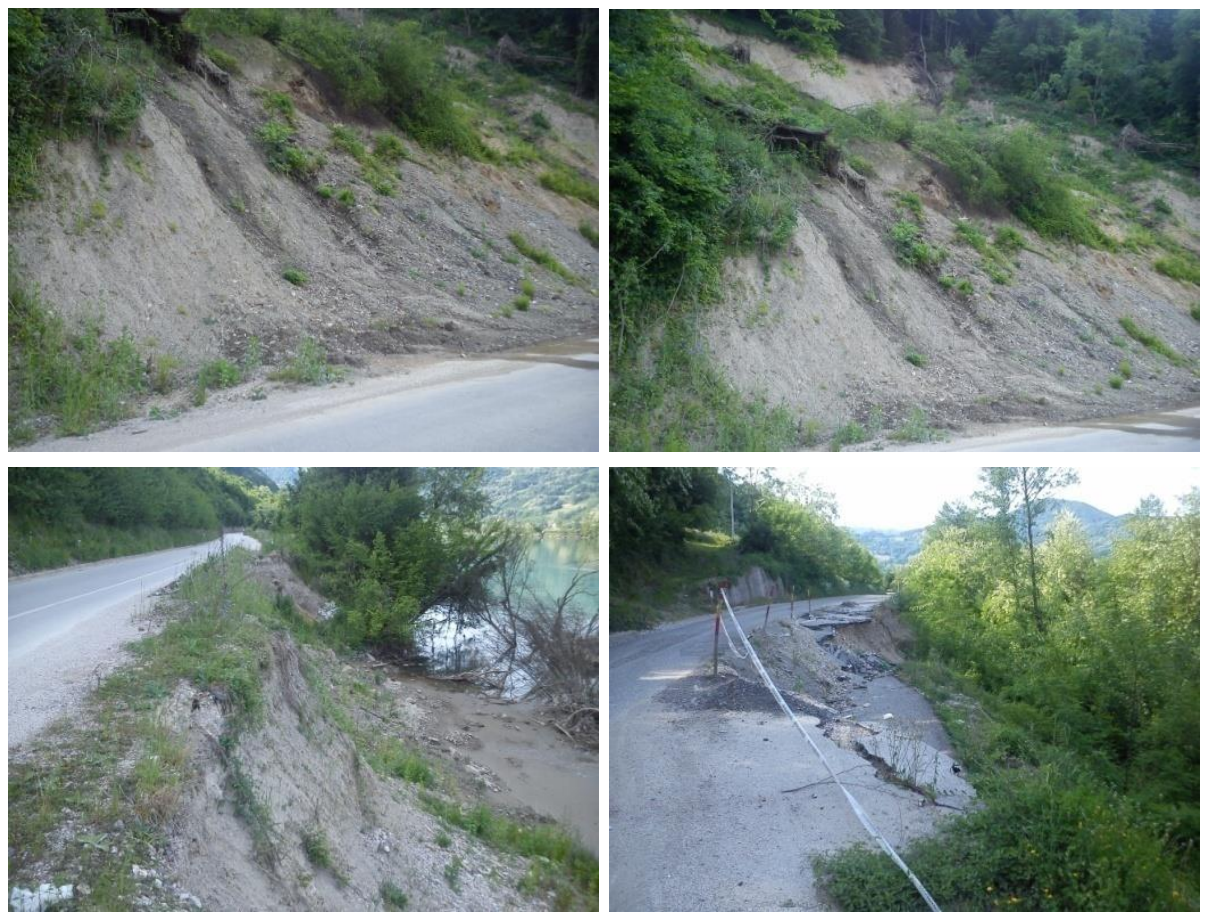

Slika 2. Klizišta na regionalnom putu Drinjača - Bratunac, iznad i ispod trase puta

Na regionalnom putu Bijeljina - Srebrenik koji prolazi uglavnom kroz uslovno stabilne terene, registrovano je više klizišta. Pojavila su se na dionicama koje su asfaltirane početkom XXI vijeka u etapnim fazame bez prethodnih proučavanja terena i izrade projektne dokumentacije. Trasa puta koja je godinama bila stabilna kao makadamski put, sada je oštećena u mjeri da je na pojedinim mjestim potpuno prekinuta. Povremene brze sancije, samo su pogoršavale stanje poslije novih padavina. Broj nastalih klizišta vjerovatno je najveći u odnosu na dužinu dionice. Jednostavno se klizišta nastavljaju jedno na drugo, a ipak meusobno su odvojena, slika 3. Klizišta su pored trase oštetila ili uništila veći broj indiviualnih stambenih objekata $[1,8,11]$. 
Савремена достигнућа у грађевинарству 22. април 2016. Суботица, СРБИЈА
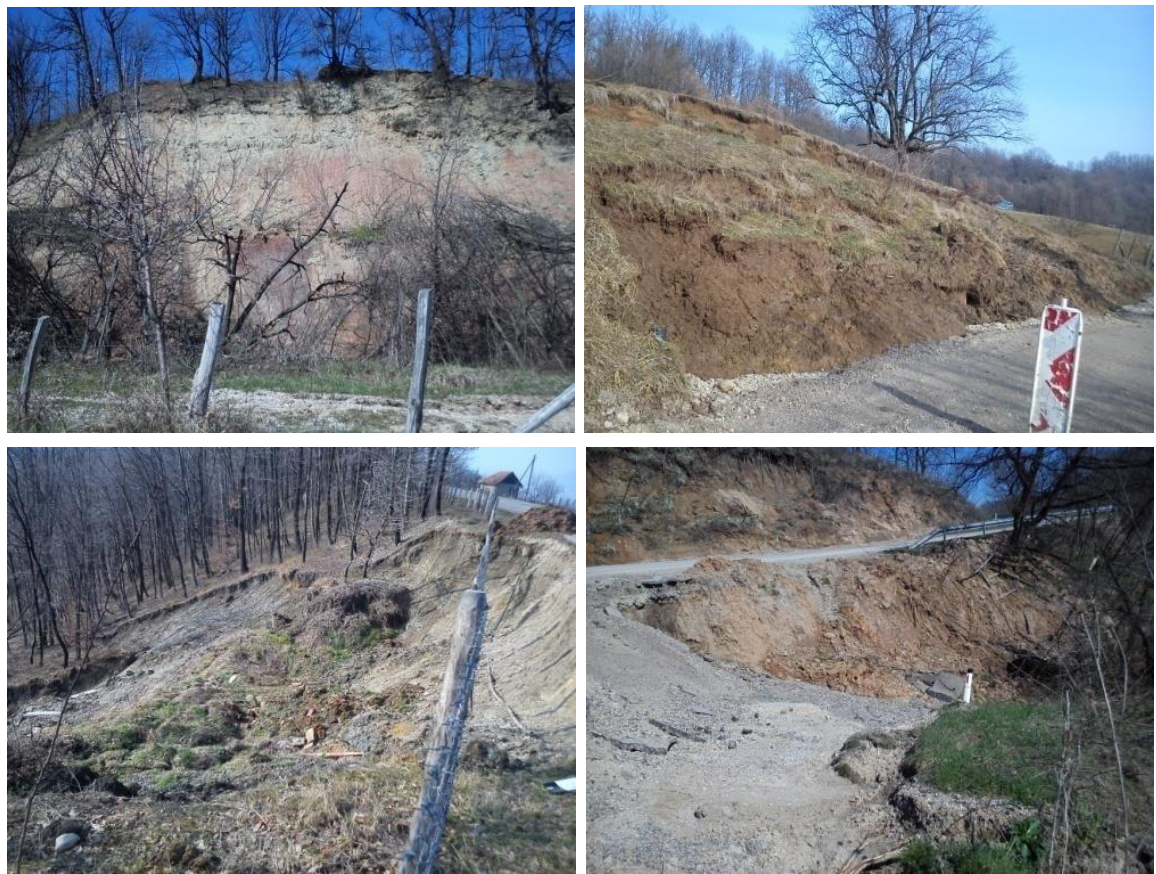

Slika 3. Klizišta na regionalnom putu Bijeljina - Srebrenik

Klizišta nastala kao rezultat stihijskih procesa, ponekad mogu biti takvih razmjera, da njihov značaj sa aspekta proučavanja prevazilazi posljedice koje su nastale na terenu ili objektima. Karakteristična su po tome što su vezana za "blokovsko pomjeranje stijenskog masiva", slika 4.

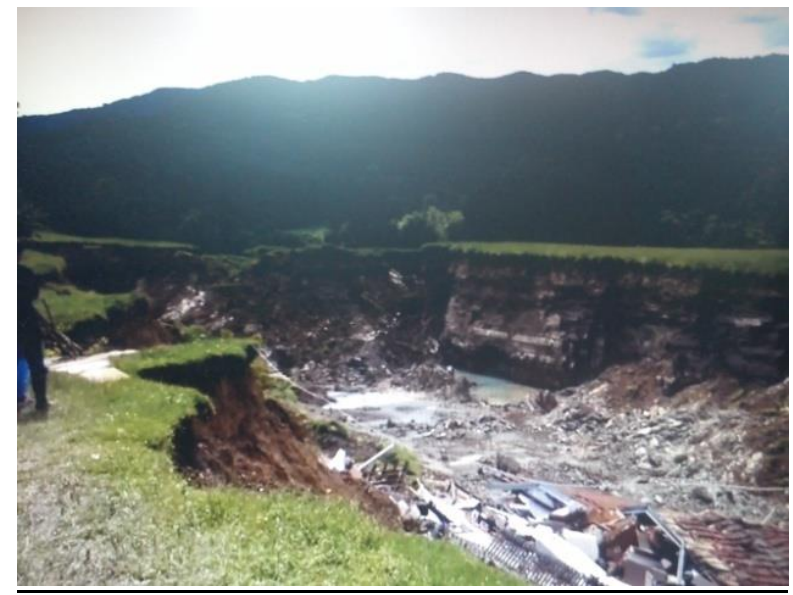

Slika 4. Blokovsko pomjeranje stijenskog masiva 
Contemporary achievements in civil engineering 22. April 2016. Subotica, SERBIA

Teren je godinama bio stabilan i na njemu su izgrađeni stambeni individualni objekti. Tokom majskih padavina 2014. godine došlo je do pucanja terena i pomjeranje jednog njegovog dijela, a drugi dio je ostao stabilan. Nekoliko objekata se samo srušilo u trenutku kao "kula od karata" i utonulo u "rov" dimenzija oko 200 x 70 m, dubine preko $10 \mathrm{~m}$. Na otvorenom profilu "razdvojenih blokova" prisutni su ilovačasto glinoviti, laporoviti i krečnjački sedimeni, koji su povoljnih karakteritika sa aspekta stabilnosti terena, posmatrano na mikro lokaciji [1,11]. Navedeni primjeri su samo neki koji su karakteristični sa aspekta uspješne i neuspješne sanacije u toku izgradnje puta, zatim osavremenjavanja puteva bez projektne dokumentacije i kao rezultat stihijskih procesa.

\section{DISKUSIJA}

Nastala problematika u protekle tri godine od strane ekstremno visokih padavina pokazuje da su značajnu ulogu u oštećenju objekata imali stihijski i antropogeni procesi. U kojoj mjeru su neki značajniji, važno je sagledati samo u dijelu izgradnje objekata, odnosno gdje su vršene inženjerske aktivnosti. Stihijski procesi i pojave vezane za terene koji nisu predmet interesovana čovjeka su manje značajni i oni će uglavnom ostati samo djelimično registrovani, ali ne i proučavani. Vremenom će se pojave nastale od tih procesa umiriti, obrasti biljnim pokrivačem i činiti neki novi morfološki oblik koji predstavlja uslovno stabilni dio terena. Stihijski i antropogeni procesi nastali u dijelu izgrađenih objekta značajni su sa aspekta osposobljavanje objekata za dalje funkcionisanje ili potpuno napuštanje tih objekata, pri tome tražeći za njih nova rješenja. Za njihovo sagledavanje potrebno je detaljno geološko istraživanje terena i procesa koji su nastali i doveli do oštećenja, te prijedlozi mjera uspješne i trajne sanacije. Obzirom na veliki broj objekata sa različitim stepenom oštećenja i potrebom za brzom intervencijom, veći dio objekata se može brzo sanirati privremenim mjerama uz prethodno sagledavanja karakteristika terena i uzroka nastalih procesa. Objekti građeni do devedesetih godina XX vijeka su dosta stabilniji, tako da su i u periodu navedenih padavina ostali neoštećeni ili samo ponegdje oštećeni u padinskom dijelu gdje su loše održavane u prethodnom periodu. Rezultat toga je kvalitetniji pristup proučavanju terena, građenja i održavanja objekata. Poslije navedenog perioda mijenja se odnos prema građenju objekata, koji se nije pokazao loše samo u periodu intenzivnih padavina, već tokom cijelog navedenog perioda. Dosta primjera imamo da klizišta ili neke druge pojave nastanu prije završetka objekta, ili nešto kasnije, posebno u proljetnom periodu kada je veće prisustvo voda u stijenskim mterijalima. Intenzivne padavine samo su ubrzale neke procese koji su bili na granici ravnoteže, od kojih bi neki nastali u narednom periodu uz normalne padavine karakteristične za neko područje. Važno je istaći da padavine ili neke druge vrste elementarnih nepogoda ne mogu narušti stabilnost padina i ugroziti objekte ukoliko je pristup građenju bio na zadovoljavajućem nivou, počev od faze proučavanja terena, građenja objekata i njihovim upravljanem tokom vremena korištenja. Kvalitetno urađeni i održavani objekti izdržali su sve nepogode, što potvrđuje opravdanost i potrebu za detaljnijim proučavanjem karakteristika terena i kvaletetnijim građenjem. Klimatske oscilacije tokom godine sve su značajnije, što otvara razmišljanje i stvara obavezu u pravcu nastanka teorije "uspostava ravnotežnog stanja u novim prirodnim uslovima 
diktiranim savremenim tehnološkim razvojem". U oblasti praćenja savremenih egzogenih procesa, gdje klizišta imaju najznačajniju ulogu, klimatske promjene, odnosno meteorološki faktor se pokazuje kao najznačajniji koji ostavlja posljedice lokalnog značaja, posmatrano u širem prostoru.

\section{LITERATURA}

[1] Đurić N. (2015). Klizišta kao posljedica višednevnih majskih poplava 2014. - da li je tako moralo biti ???. Banja Luka. 2015. Naučni skup sa međunarodnim učešćem “Klizišta u Republici Srpskoj kao posljedica višednevnih padavina u maju 2014”. Akademija nauka i umjetnosti Republike Srpske. Naučni skupovi, knjiga XXXVII, Odjeljenje prorodno-matematičkih i tehničkih nauka, knjiga 28, str. 15-37.

[2] Đurić, N., Škripić, N., Alihodžić, M. Pregled utjicaja i rizika od poplava i aktivnih klizišta. Izvještaj za UNDP BiH, Sarajevo. 2014.

[3] Đurić, N. Klizišta u Republici Srpskoj nastala tokom intenzivnih padavina 2014. godine. Fond stručne dokumentacije. Tehnički institut Bijeljina, Bijeljina. 2014.

[4] Đurić, N. Nekoliko primjera istraživanja i sanacije karakterističnih klizišta u Republici Srpskoj. Bijeljina. 2010. Arhiv za tehničke nauke br. 3, str 52-64.

[5] Đurić, N. Survey of some landslides in the Republic of Serpska. Dubrovnik. 2010. Risk identification and land-use planning for disaster mitigation of landslides and floods in Croatia“.

[6] Rokić, Lj. Fizička geologija. Ljubomir Rokić. Sarajevo. 2011.

[7] Đurić, N. Hidrogeološka i inženjerskogeološka istraživanja. Građevinski fakultet Subotica, Tehnički institut Bijeljina. Subotica, Bijeljina. 2011.

[8] Đurić, N. Kratak pregled nekih klizišta u Republici Srpskoj nastala duž trase puteva tokom majskih padavina 2014. Srebrenica. 2015. I Rudarsko-geološki forum "Stanje $i$ dalji pravci razvoja sa posebnim osvrtom na privatizaciju, koncesionarstvo i legislativu”, str. 105-111.

[9] Đurić, N., Mitrović P., Perišić M. Geotehnička istraživanja i sanacija klizišta „Polom“ na putu Drinjača - Bratunac. Bijeljina. 2009. Arhiv za tehničke nauke“ br. 1 , str. 1-8.

[10] Mitrović, P. (2001). Primjena plastičnih materijala pri sanaciji i melioracijama terena. Donji Milanovac. 2001. Istraživanje i sanacija klizišta.

[11] Đurić N., Bešević M., Đurić D., Prokić A., Kukaras D. Causes and Consequences of Certain Landslides in Republic of Srpska, Bosnia and Herzegovina. Prag. 2015. World Multidisciplinary Earth Sciences Symposium, WMESS 2015. Procesia Earth and Planetary Science 15, pp. 159-164. www.sciencedirect.com

\section{MODERN CONSTRUCTION OF OBJECTS AND CONTEMPORARY LANDSLIDES}

Summary: Construction of facilities as one of the oldest trades during time developed to such extent that today it represents an important scientific field. Numerous buildings 
Contemporary achievements in civil engineering 22. April 2016. Subotica, SERBIA

were built above and below ground during the past human civilization. Some were more or less significant, but basically they all had a unique objective to be of good quality and long lasting. How much was that succeeded? Earlier much less, and today it is required to have full safety and durability.

Intensive construction during the $X X$ and the beginning of XXI century required next to development of science construction, also development of other sciences, primarily geological which study the rock mass where and in which are constructed the objects. It has been developed a special scientific field of geotechnics that include engineering geological studies of the characteristics of the terrain and rock masses in the natural state, which serve as a basis on which to plan and build certain objects. Today there are no buildings in the air, all are related to the surface or just below the ground surface, which requires more detailed study. Construction science has achieved a high degree of perfection in the part of structural stability of objects, but it is still a step behind in the construction connection of the object with the substrate on which or in which it is built.

Intensive construction of facilities at the end of XX and beginning of the XXI century, which coincided with the changing social and property relations, partly neglected so far planned constructions, both in terms of space usage and ways of construction. Somewhere is missing partly and somewhere a complete part of previous trainings in the field of studying of characteristic of the terrain and designing of objects harmonized with the terrain. All is quickly built without taking into account the quality of construction and possible consequences during and after construction. It is particularly expressed in high-rise buildings, primarily linear objects This period may be called the period of "modern construction of objects", which is not organized, professional and scientific isolated like that, but it is self-imposed. The negative results of the construction of objects in this period are visible during or after construction, especially at a time of intense precipitation, which affected this area three times in the last three years. Natural disasters are a warning for what has been done wrong or omitted to be done in the construction of objects, and to refer back to the period of study of good terrain and a better quality of construction.

These considerations were created after visiting a large number of landslides in Bosnia and Herzegovina. It was done in the context of one of the projects of UNDP, and in the work was given a review of the issues arising given and a display of some characteristic landslides.

Keywords: modern construction, landslides, engineering activities, precipitation consequences 